\title{
Aplicação exógena do ácido salicílico em maracujazeiro-amarelo para o controle do vírus do endurecimento dos frutos
}

\author{
Exogenous application of salicylic acid in yellow \\ passion fruit for the control of fruit woodiness virus
}

\author{
Manassés dos Santos Silva ${ }^{1 *}$, Rômulo Pereira da Silva', Aline Vaz Laranjeira de Souza', \\ Yan Pablo Moreira Xavier ${ }^{1}$, Antonio Carlos de Oliveira ${ }^{2}$, Danila Souza Oliveira Coqueiro'
}

RESUMO: Foram avaliados o efeito do ácido salicílico (AS) no controle do Cowpea aphid-borne mosaic virus (CABMV), vírus que induz o endurecimento dos frutos do maracujazeiro (EFM), e a sua influência na expressão dos sintomas e na ativação das enzimas peroxidase e polifenoloxidase. O experimento foi delineado e conduzido de forma inteiramente casualizada. Os tratamentos consistiram em AS (2,5 mM) e controle (etanol 10\%), aplicados 12 horas antes da inoculação mecânica do CABMV, agente causal do EFM no Brasil. Um experimento similar foi conduzido sob as mesmas condiçóes, porém, quatro aplicaçôes do AS foram realizadas semanalmente após a inoculação mecânica do CABMV. Em ambos os experimentos a avaliação da severidade da doença foi realizada empregando escala de notas que variaram de 0 a 3. Para avaliar a atividade das enzimas peroxidase e polifenoloxidase, as plantas foram tratadas (AS e controle) e, após 12 horas, inoculadas com o isolado de CABMV. Foram realizadas amostragens foliares $0,12,24$ e 48 horas após os tratamentos (HAT), que foram processadas e analisadas em espectrofotômetro para a constatação da ativaçáo da peroxidase e polifenoloxidase. Aos 30 dias após a inoculação (DAI), o AS aplicado uma única vez promoveu reduçáo da severidade de $57,1 \%$, quando comparado com o controle. Nas plantas submetidas às aplicaçóes semanais de AS foi constatada a reduçáo significativa da expressão dos sintomas aos 45 DAI. Nos ensaios bioquímicos foi observado aumento significativo de peroxidase nos intervalos de 12 horas (DAI)/24 horas (HAT). Para polifenoloxidase foi observado um aumento significativo de sua atividade nos intervalos de 24 horas (DAI)/48 horas (HAT). Sugere-se que o AS pode representar uma ferramenta adicional no manejo do EFM.

PALAVRAS-CHAVE: Cowpea aphid-borne mosaic virus; eliciador; fitopatógeno; indução de resistência; virose.
ABSTRACT: The effect of salicylic acid (SA) was evaluated in control of Cowpea aphid-borne mosaic virus (CABMV), which induces hardening of the fruits of passion fruit (EFM). Also, its influence on the expression of symptoms and the activation of peroxidase and polyphenol oxidases were evaluated. The experiment was designed and conducted in a completely random way. The treatments consisted of SA $(2.5 \mathrm{mM})$ and control (10\% ethanol), applied 12 hours before mechanical inoculation of CABMV, the causal agent of EFM in Brazil. A similar experiment was conducted under the same conditions, but four applications were performed weekly after CABMV mechanical inoculation. In both experiments a rating scale ranging from 0 to 3 was used to assess the severity of the disease. To evaluate the activity of peroxidase and polyphenol oxidase, the plants were treated (SA and control) and, after 12 hours, inoculated with isolated CABMV. Leaf samplings were performed at 0,12, 24 and 48 hours after the treatments (HAT), processed and analyzed in a spectrophotometer to verify the activation of peroxidase and polyphenol oxidase. At 30 days after inoculation (DAI), the SA applied once promoted reduction of $57.1 \%$ of the severity, when compared with the control. In plants subjected to SA weekly applications, it was found a significantly reduction in the expression of symptoms at 45 DAI. In the biochemical assays, a significant increase in peroxidase in 12-hour intervals (DAI)/24 hours (HAT) was observed. For polyphenol oxidase, a significant increase of its activity was observed at 24 hour intervals (DAI)/48 hours (HAT). It is suggested that SA may represent an additional tool in the management of EFM.

KEYWORDS: Cowpea aphid-borne mosaic virus; eliciting; phytopathogen; induction of resistance; virose.

'Instituto Multidisciplinar em Saúde, Universidade Federal da Bahia (UFBA) - Anísio Teixeira (BA), Brasil.

${ }^{2}$ Departamento de Ciências Naturais, Universidade Estadual do Sudoeste da Bahia (UESB) - Vitória da Conquista (BA), Brasil.

*Autor correspondente: manasses.tec@hotmail.com

Recebido em: 01/02/2015. Aceito em: 10/06/2016 


\section{INTRODUÇÃO}

O Brasil é o maior produtor mundial de frutos de maracujá-amarelo (Passiflora edulis Sims f. flavicarpa Delg), com uma produção anual estimada em mais de 770 mil toneladas. Desse montante, mais de 320 mil toneladas são produzidas no estado da Bahia, que se destaca como o maior produtor nacional (IBGE, 2012).

Com a expansão da área cultivada no Brasil, um dos fatores limitantes para o desenvolvimento da cultura são as doenças, dentre elas se destaca o endurecimento dos frutos do maracujazeiro (EFM), causado pelo Cowpea aphid-borne mosaic vírus (CABMV), espécie pertencente ao gênero Potyvirus, família Potyviridae, classificada e aceita pelo Comitê Internacional de Taxonomia de Vírus (ICTV) como CABMV (ADAMs et al., 2012). Diante desse fato, o EFM éa doença mais importante da passicultura no Brasil e se encontra disseminada em todas as regióes produtoras (NASCIMENTO et al., 2006).

O controle do EFM nas áreas produtoras não é eficiente, devido à sua transmissão não circulativa realizada durante as picadas de prova efetuadas por diversas espécies de afídeos (Aphididae), fato que inviabiliza a indicação da aplicação de inseticidas para evitar a disseminaçấo do CABMV (REzende, 2006). Além da transmissão por afídeos, o CABMV pode ser transmitido por enxertia e durante os tratos culturais de poda de formação e desbaste (FonseCA, 2008).

Segundo Rezende (2006), os sintomas induzidos pelo CABMV se caracterizam pela presença de mosaico acompanhado, em alguns casos, de enrugamento, bolhas e distorção foliar. A doença causa a redução da produção quantitativa e qualitativa, já que os frutos são menores, deformados e endurecidos, além de apresentarem endocarpo expandido e redução na produçáo de polpa. Os frutos são depreciados por esses sintomas e tornam-se inviáveis para o consumo (GIORIA et al., 2000).

O controle de doenças de plantas, principalmente aquelas causadas por fungos, pode ser efetivo empregando-se métodos convencionais (aplicaçáo de agroquímicos) e alternativos (controle biológico, rotação de culturas, solarização, biofumigação, utilizaçáo de extratos de plantas e outros compostos naturais) (PATricio, 2007). Em se tratando de doenças causadas por vírus, o meio mais indicado para o controle ainda é a obtenção de variedades que possuam genes que confiram resistência vertical à doença (VAN DER PLANK, 1963).

Nesse sentido, o controle do EFM, em maracujazeiros, pode ser incrementado com a utilizaçáo de indutores de resistência, à semelhança dos estudos relatados por Oliveira et al. (2007). A induçâo de resistência, além de ocorrer devido à infecçáo localizada, pode ocorrer também por tratamentos com eliciadores, compostos que modulam a defesa da planta e podem melhorar a capacidade de respostas de várias espécies vegetais à infecção por patógenos (BoNALdo et al., 2005).

Dentre os compostos amplamente pesquisados na interação planta-patógeno, encontra-se o ácido salicílico (AS) (Leite et al., 1997). O AS é um composto fenólico encontrado nas plantas e que desempenha açáo sinalizadora de defesa contra patógenos, podendo culminar com a expressão de genes de resistência (MaUCh-Mani; MÉTraUX, 1998). Várias pesquisas mostram que aplicaçôes exógenas do AS podem influenciar na reduçáo dos sintomas de doenças em plantas, podendo promover $\mathrm{o}$ acúmulo de proteínas relacionadas à patogênese (PRs) que atuam como defesa, podendo-se citar as peroxidases e polifenoloxidases (Maia et al., 2000; CarvalHo, 2006; Mandal et al., 2009).

Desse modo, faz-se necessária a investigação de métodos alternativos no controle do EFM, uma vez que ainda não existem substâncias eficientes no controle da doença. Assim, o presente trabalho objetivou avaliar o efeito do AS no controle da virose do endurecimento dos frutos no maracujazeiro-amarelo.

\section{MATERIAL E MÉTODOS}

\section{Obtenção das mudas de maracujazeiro-amarelo}

Para obtenção das mudas de maracujazeiro-amarelo procedeu-se a semeadura da variedade BRS Gigante-Amarelo em sacos de polietileno (2 L) contendo substrato composto por terra e esterco de gado $(4: 1 \mathrm{v} / \mathrm{v})$. As mudas obtidas foram mantidas em casa de vegetaçấo até o estágio de desenvolvimento relativo a quatro folhas verdadeiras, quando entâo foram utilizadas para a realização dos experimentos.

\section{Obtenção do inóculo de Cowpea aphid-borne mosaic virus}

O isolado de CABMV, denominado UESB-9, utilizado nos ensaios para a avaliação do efeito da aplicação de AS, foi obtido a partir de amostras de folhas sintomáticas de maracujazeiro-amarelo, cuja identificação foi realizada pelo Laboratório de Genética de Plantas da Universidade Estadual do Sudoeste da Bahia (UESB). O inóculo para inoculaçáo mecânica das mudas de maracujá foi obtido a partir da maceração de folhas de maracujá-amarelo infectadas em tampão fosfato $0,02 \mathrm{M}, \mathrm{pH} 7$ na proporção de 2:10 $(\mathrm{p} / \mathrm{v})$, utilizando almofariz e pistilo. O extrato obtido foi friccionado sobre o limbo foliar das mudas de maracujá-amarelo juntamente com abrasivo carburundum e foram mantidas em casa de vegetação para a observação dos sintomas (NovAEs, 2002).

\section{Aplicação do ácido salicílico e inoculação das mudas de maracujá para avaliação da severidade do endurecimento dos frutos do maracujazeiro}

Mudas de maracujazeiro-amarelo foram previamente tratadas com a aspersão de $10 \mathrm{~mL}$ da soluçáo de AS $(2,5 \mathrm{mM})$ 
dissolvida em etanol 10\%. Como controle foi aplicado o mesmo volume de etanol 10\%, empregado na dissolução do AS. Decorridas 12 horas após os tratamentos (HAT), as mudas foram inoculadas com o isolado CABMV UESB-9. A severidade dos sintomas induzidos pelo isolado de CABMV, nas mudas desafiadas, foi avaliada aos 30 e 45 dias após a inoculação (DAI).

Um segundo experimento foi conduzido de acordo com as condiçôes descritas anteriormente, porém, as aplicaçóes de AS $(2,5 \mathrm{mM})$ e controle foram realizadas semanalmente, totalizando quatro aspersôes. Nesse caso, as avaliaçóes da severidade dos sintomas foram realizadas aos 30, 45, 60, 90 e 150 DAI.

Nos dois experimentos a avaliaçấo da severidade foi baseada em uma escala de notas de 0 a 3 , em que: 0 = ausência de sintomas de mosaico; 1 = mosaico leve e sem deformaçóes foliares; 2 = mosaico severo e sem deformaçóes foliares; $3=$ mosaico severo com bolhas e deformaçôes foliares (NovaEs, 2002).

\section{Determinação da atividade de peroxidase e polifenoloxidase}

Para determinar a atividade de peroxidase e polifenoloxidase nas mudas de maracujazeiro-amarelo submetidas ao tratamento com AS (2,5 mM) e controle, amostras foliares ( 2 folhas por planta) foram coletadas nos períodos 0, 12, 24 e 48 HAT, pesadas e imediatamente congeladas a $-20^{\circ} \mathrm{C}$. Para as análises em espectrofotômetro, as amostras congeladas foram maceradas com auxílio de almofariz e pistilo, sendo este processo conduzido a $4^{\circ} \mathrm{C}$.

Para peroxidase, as amostras maceradas foram homogeneizadas por 2 minutos em $2 \mathrm{~mL}$ de tampão acetato de sódio $0,1 \mathrm{M}(\mathrm{pH} 5,2)$ contendo ácido etilenodiamino tetra-acético (EDTA) $1 \mathrm{mM}$. A solução obtida foi centrifugada a $20.000 \mathrm{~g}$ por 30 minutos a $4^{\circ} \mathrm{C}$ e o sobrenadante (extrato proteico) recuperado para análise. A atividade de peroxidase foi determinada através de método espectrofotométrico direto $(470 \mathrm{~nm})$, pela medida da conversão do guaiacol em tetraguaiacol em temperatura controlada de $30^{\circ} \mathrm{C}$. Para tanto, foram adicionados $10 \mu \mathrm{L}$ do extrato proteico a $2,9 \mathrm{~mL}$ de tampão fosfato $50 \mathrm{mM}$ (pH 6,0) contendo guaiacol 20,2 mM e peróxido de hidrogênio $90 \mathrm{mM}$. A reação foi conduzida por 4 minutos a $30^{\circ} \mathrm{C}$, com os valores de densidade óptica obtidos a cada 30 segundos. Os resultados da atividade enzimática foram expressos em $\Delta$ (delta) de absorbância.min ${ }^{-1} \cdot$ gpf $^{-1}$ (Lusso; Pascholati, 1999).

Para a atividade de polifenoloxidase, as amostras foram homogeneizadas por 2 minutos em $2 \mathrm{~mL}$ de tampáo acetato de sódio $0,1 \mathrm{M}(\mathrm{pH} 5,0)$ e centrifugadas a $20.000 \mathrm{~g}$ por 30 minutos a $4^{\circ} \mathrm{C}$, obtendo-se o sobrenadante (extrato proteico). A atividade da polifenoloxidase foi mensurada utilizando o catecol $20 \mathrm{mM}$, como substrato, dissolvido em tampão fosfato de sódio $0,1 \mathrm{M}(\mathrm{pH} 6,8)$. A reação se desenvolveu a partir da mistura de $900 \mu \mathrm{L}$ do substrato com $100 \mu \mathrm{L}$ do extrato proteico mantidos a uma temperatura de $30^{\circ} \mathrm{C}$. A leitura foi feita de forma direta em espectrofotômetro $(420 \mathrm{~nm})$. Os resultados foram expressos em absorbância.min ${ }^{-1} \cdot$ gpf $^{-1}$ (DuAngmal; Apenten, 1999).

\section{Análises estatísticas}

Todos os experimentos foram conduzidos utilizando delineamento inteiramente casualizado com três repetiçôes por tratamento ( 1 repetição $=1$ muda). Os dados foram submetidos ao teste de normalidade (Kolmogorov-Smirnov) e, quando a distribuição foi normal, foi utilizado teste $t$ de Student para verificar diferença significativa entre os resultados médios dos tratamentos. Quando os dados não apresentaram distribuição normal, foram transformados em escala logarítmica. Os dados, cujo padrão assimétrico foi mantido após a transformação logarítmica, foram submetidos ao teste não paramétrico Mann-Whitney. As análises foram conduzidas utilizando o software Bioestat 5.3 (Ayres et al., 2007).

\section{RESULTADOS E DISCUSSÃO}

A concentração do AS $(2,5 \mathrm{mM})$ e o intervalo entre o tratamento das plantas e a inoculação (12 HAT) foram determinados em experimento preliminar (dados não mostrados). Em nenhum dos experimentos foi observado efeito fitotóxico do AS nas mudas de maracujazeiro-amarelo tratadas com o composto e desafiadas com o vírus.

A partir das avaliaçóes da severidade foi observado que as plantas submetidas a uma única aplicação com AS apresentaram redução da severidade dos sintomas, quando comparadas com o controle (Fig. 1). Aos 30 DAI, notou-se uma diferença significativa entre os tratamentos, sendo que as plantas tratadas

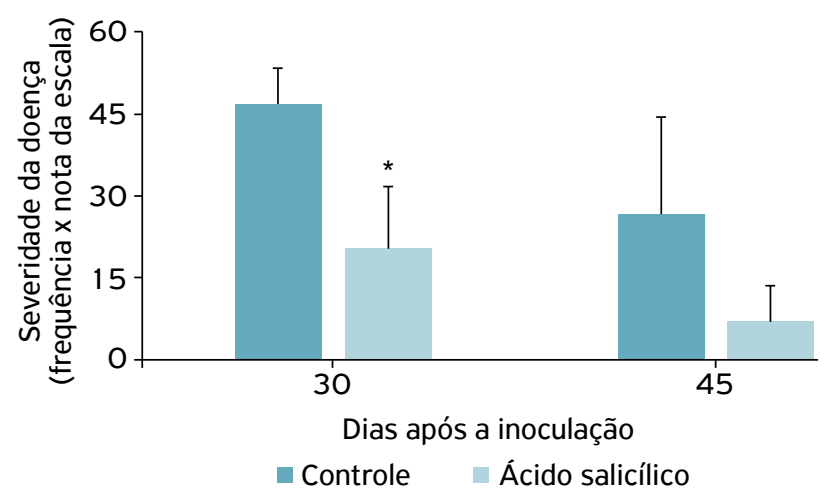

*Diferença significativa entre os resultados médios dos tratamentos aos 30 dias após a inoculação pelo teste $t$ de Student $(p=0,005)$; barras indicam média \pm erro padrão.

Figura 1. Severidade do endurecimento dos frutos em maracujazeiro-amarelo em função do tratamento com ácido salicílico 2,5 mM e controle (etanol 10\%), pulverizados uma única vez, em condições de casa de vegetação. 
com o AS apresentaram sintomas mais brandos, quando comparadas com o controle (Fig. 1).

No ensaio em que foram realizadas aplicaçóes semanais do AS foi constatado que, em plantas submetidas ao tratamento, os sintomas se desenvolveram aos 60 DAI, ou seja, 15 dias após os primeiros sintomas observados no controle (Fig. 2). A severidade foi menor em plantas tratadas com AS até os $60 \mathrm{DAI}$, sendo que aos $45 \mathrm{DAI}$ observou-se diferença significativa entre os tratamentos (Fig. 2).

Foi avaliada a atividade de duas importantes enzimas associadas à defesa de plantas, a peroxidase e a polifenoloxidase. Antes da inoculaçáo com o vírus (12 HAT), foi observado que o AS promoveu um acréscimo na atividade de peroxidase (Fig. 3). Depois de 24 HAT, houve um significativo aumento na atividade de peroxidase quando comparado com o controle, mas com 48 HAT os tratamentos não diferiram entre si (Fig. 3).

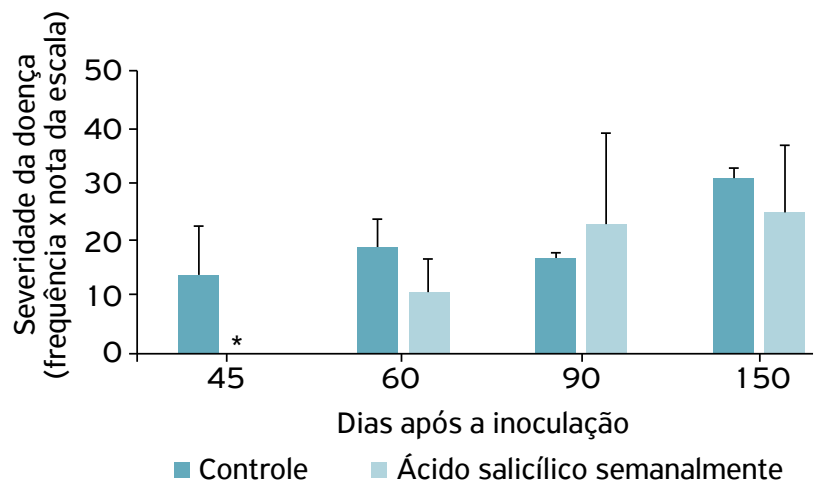

*Diferença significativa entre os resultados médios dos tratamentos aos 45 dias após a inoculação pelo teste Mann-Whitney $(p=0,037)$; barras indicam média \pm erro padrão.

Figura 2. Severidade do endurecimento dos frutos em maracujazeiro-amarelo em função do tratamento com ácido salicílico 2,5 mM e controle (etanol 10\%), pulverizados semanalmente em um total de quatro aplicações, em condições de casa de vegetação.

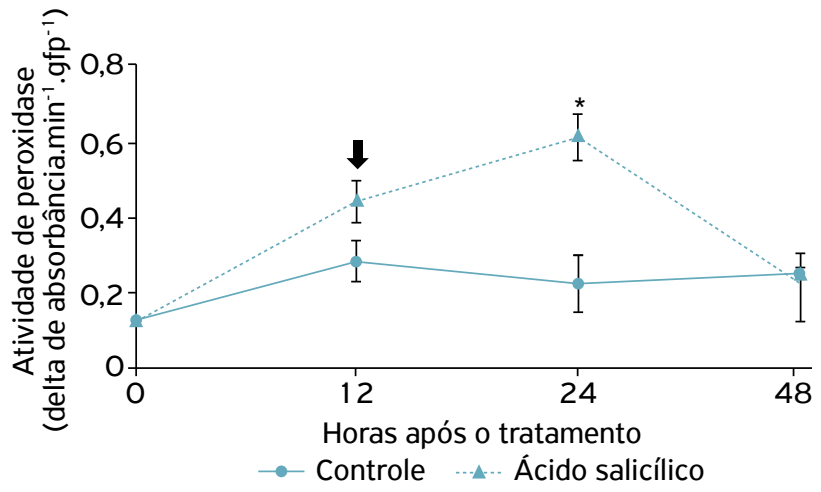

*Diferença significativa entre os tratamentos pelo teste $t$ de Student ( $p=0,017$ ); barras indicam média \pm erro padrão; seta indica o momento da inoculação do isolado Cowpea aphid-borne mosaic virus UESB-9.

Figura 3. Atividade de peroxidase em mudas de maracujá-amarelo tratadas com ácido salicílico 2,5 mM e etanol $10 \%$ (controle) em diferentes tempos de coleta.
Não foi observado aumento na atividade da polifenoloxidase até 24 HAT (período correspondente a 12 horas após a inoculação) (Fig. 4). Entretanto, houve um aumento tardio da atividade dessa enzima comparada à peroxidase, pois em 48 HAT foi observado que em plantas tratadas com AS a atividade de polifenoloxidase foi maior, quando comparadas com as plantas controle (Fig. 4).

Investigaçôes acerca da aplicação exógena de AS em plantas revelaram que esse composto é capaz de induzir resistência sistêmica e promover a síntese do próprio AS e o acúmulo de PRs (Raskin, 1992; Spletzer; Enyedi, 1999; Repka et al., 2001; TERrY; JoYCE, 2004).

No presente estudo foi observado que o AS promoveu reduçóes significativas da severidade dos sintomas do EFM, seja quando aplicado uma única vez ou semanalmente. Notou-se que aplicações semanais do AS promoveram uma resposta tardia da planta à infecção pelo CABMV (até $45 \mathrm{DAI}$ ).

Resultados similares, em termos de redução sintomatológica, foram obtidos por Hooft VAN HuIJSDUIJNEN et al. (1986), que observaram que aplicaçóes exógenas de AS $(0,25 \mathrm{M})$ em plantas de feijão reduziram em até $75 \%$ as lesôes locais causadas pelo Alfalfa mosaic vírus (A1MV). As respostas desencadeadas pela aplicação do AS exógeno atuam em vários processos da patogênese, dentre eles a inibição da replicação do vírus (NAYLOR et al., 1998), a inibição do movimento sistêmico do vírus (MAYERs et al., 2005) e a indução de PRs (Hooft VAN Huijsduijnen et al., 1986).

Em um estudo realizado por AlaWLAQI (2014), o AS (200 $\mu \mathrm{M})$ foi aplicado em plantas de Cucurbita pepo desfiadas com o Zucchini yellow mosaic vírus (ZYMV) e foi constatada a redução da doença, sugerindo que essa resposta pode ter ocorrido pela inibição da replicação ou por dificultar a translocação do vírus. No maracujazeiro-amarelo, o CABMV pode ter encontrado dificuldades na translocaçáo para diferentes pontos da planta, seja pelo fato do AS ter atuado diretamente sobre o vírus, como mostrado por ALAWLAQI (2014), ou por barreiras formadas pela planta em resposta à aplicação do AS, como o aumento da atividade das enzimas peroxidases e polifenoloxidases avaliadas no presente estudo.

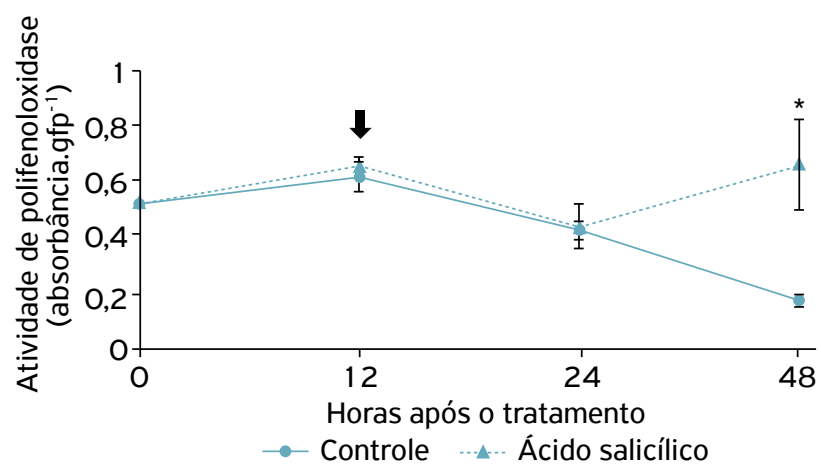

*Diferença significativa entre os tratamentos pelo teste $t$ de Student ( $p=0,008$ ); barras indicam média \pm erro padrão; seta indica o momento da inoculação do isolado Cowpea aphid-borne mosaic virus UESB-9.

Figura 4. Atividade de polifenoloxidase em mudas de maracujá-amarelo tratadas com ácido salicílico 2,5 $\mathrm{mM}$ e etanol $10 \%$ (controle) em diferentes tempos de coleta. 
Sabe-se que aplicaçóes exógenas do AS induzem a expressão de proteínas, como as peroxidases e polifenoloxidases, que estão envolvidas na indução da resistência sistêmica adquirida (SAR) (Chet, 1993; Kessmann et al., 1994). White (1979) realizou aplicaçôes exógenas do AS $(0,02 \%)$ sobre plantas de fumo (Nicotiana tabacum cv. Xanthi-nc) inoculadas com o Tobacco mosaic virus (TMV) e observou que houve aumento da atividade de glucanases, o que induziu a resistência das plantas ao TMV. Além disso, foi observada redução do número de lesôes em mais de 90\%, quando comparado ao controle. Segundo STANGARLIn et al. (2011), as glucanases também são proteínas que atuam na defesa da planta contra patógenos.

$\mathrm{O}$ aumento significativo da atividade de peroxidase, observado após a inoculação do isolado CABMV-UESB-9 no presente estudo, pode estar associado a diversos processos. Em estudo realizado por MARRiotT et al. (1978), foi observado que $\mathrm{o}$ aumento na atividade de peroxidase esteve associado ao fortalecimento da parede celular e da membrana plasmática das células, resultantes do processo da biossíntese de lignina, que atua como defesa à penetração de patógenos. Esses mecanismos estruturais, atrelados a uma resposta da peroxidase, podem ter contribuído para reduçáo dos sintomas do EFM promovidos pela aplicaçáo do AS.

Faheed; Mahmoud (2006) trataram plantas de feijão (Phaseolus vulgaris L. cv. Contender) com AS (0,1; 0,5 e $1 \mathrm{mM}$ ) e desafiaram com o Tobacco necrosis virus (TNV). Também constataram reduçáo da severidade da doença e aumento da atividade de peroxidase, quando o AS foi aplicado a $0,1 \mathrm{mM}$, corroborando os resultados obtidos em maracujazeiro-amarelo e o CABMV.

De acordo com BonatTi et al. (1994), a atividade de peroxidase pode sofrer alteraçóes por estar correlacionada com a resposta de resistência ou suscetibilidade em diferentes patossistemas. Aumentos na atividade da peroxidase, associados a ferimentos em vegetais, podem promover elevaçóes na concentração de produtos de oxidação de fenólicos, alterando a concentração de auxinas (AIA) devido à presença de AIA-oxidase (MARriotT et al.,1978).

Já a importância da atividade da polifenoloxidase na resposta à infecçáo deve-se, provavelmente, à sua propriedade em oxidar fenol a quinonas, uma vez que esses compostos fenólicos são tóxicos aos micro-organismos (ZHENG et al., 1999; Agrios, 2004). A ação da polifenoloxidase processa-se por meio da hidroxilação de monofenóis para o-difenóis e oxidação desses o-difenóis para quinonas (Wheatley, 1982). Por sua vez, as quinonas se acumulam nas paredes celulares promovendo o aumento da resistência à penetração do patógeno, como é o caso dos vírus (Teixeira et al., 2011).

O aumento na atividade dessa enzima 48 HAT pode ter contribuído para a formação de barreiras que podem ter impossibilitado o avanço do vírus em várias partes da planta. Esse resultado pode ter contribuído para a redução dos sintomas observados nas plantas tratadas com AS aos $30 \mathrm{DAI}$ (quando aplicado apenas uma vez) e aos 45 DAI (quando aplicado semanalmente).

Segundo SANCHEZ et al. (2000), o nível de polifenoloxidase pode variar de acordo com a espécie e cultivar de planta e também com as condiçôes do ambiente. Sua ativação pode ser induzida por estresse, como a infecção por bactérias, fungos e vírus, que, consequentemente, promove o início do processo de oxidação dos compostos fenólicos que poderão impedir a penetração do patógeno. A polifenoloxidase atua na produção de lignina, que atua como uma barreira estrutural de defesa contra ataques de fitopatógenos e insetos (THIPYAPONG; StefFens, 1997).

Dessa forma, os dados obtidos no presente estudo sugerem que aplicaçóes exógenas de AS podem ser uma alternativa na indução de resposta de defesa para a redução da severidade dos sintomas do EFM. O AS promoveu o aumento da atividade da peroxidase e polifenoloxidase, PRs que atuam como defesa. Sugere-se que o AS pode representar uma ferramenta adicional no manejo do EFM.

\section{AGRADECIMENTOS}

Os autores agradecem à Universidade Federal da Bahia, ao Conselho Nacional de Desenvolvimento Científico e Tecnológico (CNPq) pela concessão da bolsa de pesquisa PIBIC/ $\mathrm{CNPq}$ e à Universidade Estadual do Sudoeste da Bahia pelo fornecimento do isolado de CABMV utilizado neste trabalho.
ADAMS, M.J.; ZERBINI, F.M.; FRECHA, R.; RABENSTEIN, F.; STENGER, D.C.; VALKONEN, J.P.T. Potyviridae. In: KING, A.M.Q.; ADAMS, M.J.; CARSTENS, E.B.; LEFKOWITZ, E.J. (Eds.). Virus taxonomy: ninth report of the International Committee on Taxonomy of Viruses. London: Elsevier Academic Press, 2012.p. 1069-1089.

AGRIOS, G.N. Plant pathology. 5th ed. San Diego: Elsevier Academic Press, 2004. 922p.
ALAWLAQI, M.M. Impact of salicylic acid and Juniperus procera extract as a defense mechanism against Zucchini yellow mosaic virus and host biochemical characterization. Journal of Microbiology Research, v.4, n.3, p. 141-147, 2014.

AYRES, M.; AYRES JUNIOR, M; AYRES, D.L; SANTOS, A.A.S. Bioestat 5.O: aplicações estatísticas nas áreas das ciências bio-médicas. Belém: Ong Mamiraua, 2007. 
BONALDO, S.M; PASCHOLATI, S.F.; ROMEIRO, R.S. Indução de resistência: noções básicas e perspectivas. In: CAVALCANTI, L.S.; DI PIERO, R.M.; CIA, P.; PASCHOLATI, S.F.; RESENDE, M.L.V.; ROMEIRO, R.S. (Eds). Indução de resistência em plantas a patógenos e insetos. Piracicaba: Fundação de Estudos Agrários Luiz de Queiroz, 2005. Cap. 1, p. 11-28.

BONATTI, P.M.; LORENZINI, G.; FORNASIERO, R.B.; NALI, C.; SGARBI, E. Cytochemical detection of cell wall bound peroxidase in rust infected broad bean leaves. Journal of Phytopathologiy, Berlin, v.140, n.4, p.319-325, 1994.

CARVALHO, P.R. Avaliação do uso do ácido salicílico em sementes de calêndula (Calendula officinalis L.) sob diferentes estresses. 2006. 35f. Dissertação (Mestrado em Agronomia) - Universidade do Oeste Paulista, Presidente Prudente, 2006.

CHET, I. Biotechnology in plant disease control. New York: Wiley Liss, 1993. 373p.

DUANGMAL, K.; APENTEN, R.K.O. A comparative study of polyphenoloxidases from taro (Colocasia esculenta) and potato (Solanum tuberosum var. Romano). Food Chemistry, Wageningem, v.64, n.3, p.351-359, 1999.

FAHEED, F.A.; MAHMOUD, S.Y.M. Induction of resistance in Phaseolus vulgaris against TNV by salicylic acid and kinetin. International Journal of Agriculture and Biology, v.8, n. 1, p.47-51, 2006.

FONSECA, K.G. Retrocruzamentos visando à obtenção de resistência do maracujazeiro-azedo à virose do endurecimento dos frutos, auxiliados por marcadores moleculares. 2008. 96f. Dissertação (Mestrado em Ciências Agrárias - Área de Produção Vegetal) Universidade de Brasília, Brasília, 2008.

GIORIA, R.; BOSQUÊ, G.G.; REZENDE, J.A.M.; AMORIM, L.; KITAJIMA, E.W. Incidência de viroses de maracujazeiro na Alta Paulista - SP, e danos causados pelo Passion fruit woodiness virus. Fitopatologia Brasileira, Brasília, v.25, p.182-189, 2000.

HOOFT VAN HUIJSDUIJNEN, R.A.M.; ALBLAS, S.W.; RIJK, R.H.; BOL J.F. Induction by salicylic acid of pathogenesis-related proteins and resistance to Alfalfa mosaic virus infection in various plant species. Journal of General Virology, v.67, p.2135-2143, 1986.

IBGE - INSTITUTO BRASILEIRO DE GEOGRAFIA E ESTATÍSTICA. Maracujá: área plantada e quantidade produzida. Brasília: IBGE, 2012. (Produção Agrícola Municipal, 2012). Disponível em: <http://www.sidra.ibge.gov.br>. Acesso em: 20 out. 2014.

KESSMANN, H.; STAUB, T.; HOFMANN, C.; MAETZKE, T.; HERZOG, J.; WARD, E.; UKNES, S.; RYALS, J. Induction of systemic acquired disease resistance in plants by chemicals. Annual Review of Phytopathology, v.32, p.439-459, 1994.

LEITE, B.; RONCATO, L.D.B.; PASCHOLATI, S.F.; LAMBAIS, M.R. Reconhecimento e transdução de sinais moleculares em interações planta-fungos patogênicos. In: LUZ, W.C. (Org.). Revisão Anual de Patologia de Plantas. 1 a ed. Passo Fundo: Sociedade Brasileira de Fitopatologia, 1997. Vol. 5, p. 235-280.

LUSSO, M.F.G.; PASCHOLATI, S.F. Activity and isoenzymatic pattern of soluble peroxidases in maize tissues after mechanical injury or fungal inoculation. Summa Phytopathologica, Jaboticabal, v.25, n.3, p.244-249, 1999.

MAIA, F.C.; MORAES, D.M.; MORAES, R.C.P. Ácido salicílico: efeito na qualidade de sementes de soja. Revista Brasileira de Sementes, v.22, n. 1, p.264-270, 2000

MANDAL, S.; MALLICK, N.; MITRA, A. Salicylic acid-induced resistance to Fusarium oxysporumf. sp. lycopersici in tomato. Plant Physiology and Biochemistry, v.47, n. 7, p.642-649, 2009.

MARRIOTT, J.; BEEN, B.O.; PERKINS, C. The aethiology vascular streaking in cassava roots after harvest: association with water loss from wounds. Plant Physiology, v.44, n. 1, p.38-42, 1978.

MAUCH-MANI, B.; MÉTRAUX, J.P. Salicylic acid and systemic acquired resistance to pathogen attack. Annals of Botany, v.82, n.5, p.535-540, 1998.

MAYERS, C.N.; LEE, K.C.; MOORE, C.A.; WONG, S.M.; CARR, J.P. Salicylic acid-induced resistance to Cucumber mosaic virus in squash and Arabidopsis thaliana: contrasting mechanisms of induction and antiviral action. Molecular Plant-Microbe Interactions, v.18, n.5, p.428-434, 2005.

NASCIMENTO, A.V.S.; SANTANA, E.N.; BRAZ, A.S.K.; ALFENAS, P.F.; PIO-RIBEIRO, G.; ANDRADE, G.P.; CARVALHO, M.G.; ZERBINI, F.M. Cowpea aphid-borne mosaic virus (CABMV) is widespread in passionfruit in Brazil and causes passionfruit woodiness disease. Archives of Virology, v.151, n.9, p.1797-1809, 2006.

NAYLOR, M.; MURPHY, A.M.; BERRY, J.O.; CARR, J.P. Salicylic acid can induce resistance to plant virus movement. Molecular Plant-Microbe Interactions, v. 1 1, n.9, p.860-868, 1998.

NOVAES, Q.S. Seleção de estirpes fracas do Passion fruit woodiness virus e tentativas de premunização para o controle do endurecimento dos frutos no maracujazeiro. 2002. 74f. Tese (Doutorado em Agronomia - Área de concentração Fitopatologia) - Fundação de Estudos Agrários Luiz de Queiroz, Piracicaba, 2002.

OLIVEIRA, D.S.; FERNANDES, J.R.M.; OLIVEIRA, J.S.; MENEZES, S.P.; OLIVEIRA, A.C. Indução de resistência do maracujazeiro-amarelo (Passiflora edulis f. Flavicarpa) ao vírus do endurecimento dos frutos. In: CONGRESSO PAULISTA DE FITOPATOLOGIA, 30. 2007, Botucatu, SP. Resumos. Botucatu: 2007.

PATRICIO, F.R.A. Controle de doenças de hortaliças: convencional vs. alternativo. Biológico, São Paulo, v.69, n.2, p.87-90, 2007.

RASKIN, I. Role of salicylic acid in plants. Annual Review of Plant Physiology and Plant Molecular Biology, v.43, p.439-463, 1992.

REPKA, V.; FISCHEROVA, I.; SILHAROVÁ, K. Biological activity of the elicitor released from mycelium of a grapevine isolate of the necrotrophic fungus Botrytis cinerea. Vitis, v.40, n.4, p.205- 212, 2001.

REZENDE, J.A.M. Práticas culturais para prevenção e convivência com as viroses do maracujazeiro. In: SAMPAIO, A.C.; FUMIS, T.F.; ROSSI, A.D.; ALMEIDA, A.M.; GARCIA, M.J.M. (Eds.). Manejo no controle do vírus do endurecimento dos frutos (PWV) do maracujazeiro. Jaboticabal: Multipress, 2006. p.47-58. 
SÁNCHEZ, E; SOTO, J.M.; GARCIA, P.C.; LÓPEZ-LEFEBRE, L.R.; RIVERO, R.M.; RUIZ, J.M.; ROMERO, L. Phenolic compounds and oxidative metabolism in green bean plants under nitrogen toxicity. Australian Journal of PlantPhysiology, Collingwood, v.27, n. 10, p.973-978, 2000.

SPLETZER, M.E.; ENYEDI, A.J. Salicylic acid induces resistance to Alternaria solani in hydroponically grown tomato. Phytopathology, v.89, n.9, p.722-727, 1999.

STANGARLIN, J.R.; KUHN, O.J.; TOLEDO, M.V.; PORTZ, R.L.; SCHWAN-ESTRADA, K.R.F.; PASCHOLATI, S.F. A defesa vegetal contra fitopatógenos. Scientia Agrária Paranaensis, v.10, n.1, p. 18-46, 2011

TEIXEIRA, R.A.; REIS, A.J.S.; ROCHA, M.R. Mecanismos de resistência a fitodoenças. Goiania: Universidade Federal de Goiás, 2011. 16p. Disponível em: <http://www.agro.ufg.br/up/237/o/Modelo_ Revis_o_Bibliogr_fica.pdf>. Acesso em: 16 ago. 2016.

TERRY, L.A.; JOYCE, D.C. Elicitors of induced disease resistance in postharvest horticultural crops: a brief review. Postharvest Biology and Technology, Amsterdam, v.32, n.1, p.1-13, 2004.
THIPYAPONG, P.; STEFFENS, J.C. Tomato polyphenol oxidase: differential response of the polyphenol oxidase $\mathrm{F}$ promoter to injuries and wound signals. Plant Physiology, v. 115, n.2, p.409-418, 1997.

VAN DER PLANK, J.E. Plant diseases: epidemics and control. New York: Academic Press, 1963.

WHEATLEY, C. Studies on cassava (Manihot esculenta Crantz) root post-harvest physiological deterioration. 1982. 242p. Thesis (PhD in Cassava Utilization) - University of London, London, 1982.

WHITE, R.F. Acetysalicylic acid (aspirin) induces resistance to tobacco mosaic virus in tobacco. Virology, v.99, n.2, p.410-412, 1979.

ZHENG, C.; TENG, B.; GAO, F.; WU, Z. Studies on the changes of superoxid dismutase, peroxidase and poliphenol oxidase in seed coat of soybeans after infection with soybean mosaic virus. Scientia Agricultura Sinica, Pequim, v.32, n. 1, p.99-101, 1999. 